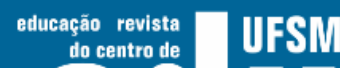 \\ GitnoahaO
}

ISSN: 1984-6444 | http://dx.doi.org/10.5902/1984644434090

\section{Cenas de práticas de ensino de matemática em narrativas de futuras professoras}

Scenes of mathematics teaching practices in the narratives of future teachers

Denise Filomena Bagne Marquesin

Professora doutora da Faculdades Anhanguera de Jundiaí, Jundiaí, São Paulo, Brasil.

Adair Mendes Nacarato

Professora doutora da Universidade São Francisco, Itatiba, São Paulo, Brasil.

Endereço: Faculdade Anhanguera de Jundiaí. R. do Retiro, 3000 - Jardim das Hortências. CEP: 13209-355. Jundiaí, São Paulo, Brasil.

E-mail: denisemarquesin@ig.com.br - adamn@terra.com.br

Recebido em 01 de agosto de 2018

Aprovado em 28 de setembro de 2018

\section{RESUMO}

Este texto tem como objetivo discutir como um contexto de produção de narrativas autobiográficas possibilitou a emergência de cenas vividas por futuras professoras, alunas na disciplina de Fundamentos e Metodologia de Matemática de um curso de Pedagogia numa instituição privada no interior do estado de São Paulo, sobre os modos de ensinar e aprender matemática. A disciplina foi ministrada por uma das autoras. O texto apoia-se nos estudos autobiográficos, que consideram as produções de narrativas como práticas de autoformação. O material para análise consistiu de 84 narrativas produzidas ao longo de um semestre. Realizou-se uma análise interpretativa dessas produções, buscando a construção de cenas de escolarização. Para este texto são apresentadas duas delas: cenas sobre os modos de ensinar matemática e cenas sobre a visão de matemática e o seu papel na sociedade. Os indícios encontrados apontam para a manutenção de metodologias de ensino de matemática, já denunciadas na literatura, como: procedimentos tecnicistas e autoritarismo do professor. Tais resultados sinalizam o quanto as reformas curriculares não chegam às salas de aula da educação básica.

Palavras-chave: Narrativas autobiográficas; Ensino de matemática; Formação dos professores dos anos iniciais. 


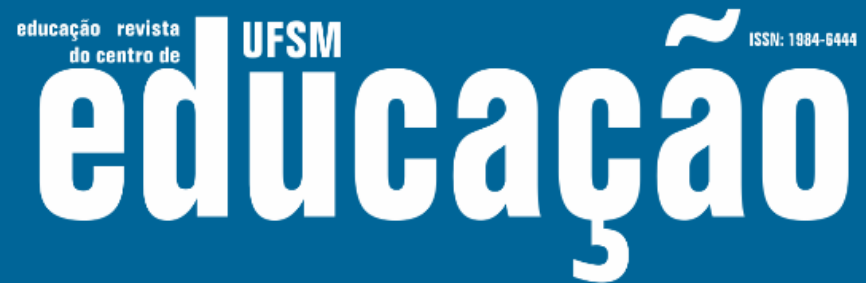

ISSN: 1984-6444 | http://dx.doi.org/10.5902/1984644434090

professoras que participaram da pesquisa. Ao nos colocarmos à escuta dessas graduandas, pudemos conhecer suas trajetórias escolares e seus espaços de aprendizagem, bem como suas crenças sobre a matemática.

Nossas reflexões teóricas tomam como ponto de partida os trabalhos de Bakhtin (2000), Bruner (1997), Clandinin e Connelly (2011), Cochran-Smith e Lytle (1999), Connelly e Clandinin (1995), Delory-Momberger (2008), Freire (1997), Josso (2004), Passeggi (2010), Pineau (2006) e Souza (2006). Tais referenciais tiveram papel significativo para a compreensão do potencial existente nas narrativas como prática de autoformação, além de constituírem ponto de partida para modalidades de pesquisa que tematizam sobre as histórias de vida, a memória, as representações sobre a profissão, os ciclos de vida, o trabalho com autobiografia, entre outros temas.

O objetivo deste texto é discutir como um contexto de produção de narrativas autobiográficas possibilitou a emergência de cenas sobre os modos de ensinar e aprender matemática vividas por futuras professoras.

O artigo está organizado em quatro seções. Inicialmente trazemos as reflexões teóricas que têm norteado o trabalho; em seguida, apresentamos o contexto de produção das narrativas autobiográficas que se tornaram dados para a pesquisa; posteriormente, apresentamos as vozes das estudantes narradoras, em cujas narrativas identificamos cenas sobre práticas de ensino de matemática, e finalizamos o texto com nossas reflexões sobre as cenas desenhadas pelas autobiografias.

\section{A produção de narrativas autobiográficas como prática formadora}

A pesquisa foi motivada por estudos, produções e inquietações sobre as potencialidades das narrativas para formação docente, que se constituíram em fontes teóricas e práticas para a adoção das escritas e o compartilhamento das narrativas autobiográficas numa disciplina do curso de Pedagogia.

Neste texto compreendemos a produção de narrativas autobiográficas como escritas de si. Pautamo-nos em trabalhos de Bruner (1997), Josso (2004) e Pineau (2006), entre outros, que consideram as narrativas autobiográficas como sinônimo de escritas de si. 


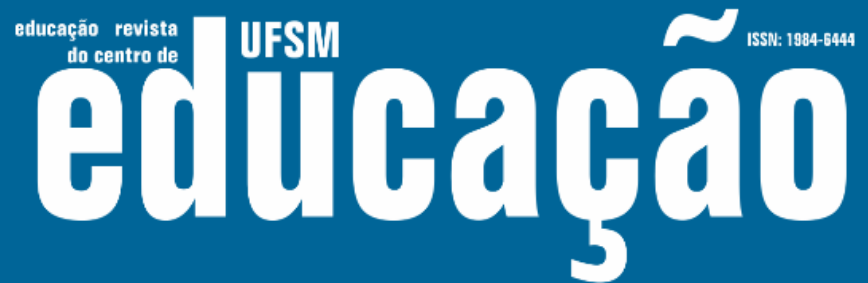

ISSN: 1984-6444 | http://dx.doi.org/10.5902/1984644434090

A expressão 'escrita de si' tem sido utilizada para fazer referência às diferentes escritas que tomam as trajetórias pessoais e profissionais em diferentes gêneros de discurso: autobiografias, narrativas de vida, memoriais de formação, narrativas de práticas, dentre outros. Assim como Clandinin e Connelly (2011), compreendemos que escrever sobre si combina vivência com autocrítica e reflexão, ou seja, escrever sobre a vida é refletir sobre ela; contudo, a escrita de si não é tarefa fácil, uma vez que essa prática envolve reflexão.

Pineau (2006) amplia as percepções sobre escritas de si, ao explicitar que é na escrita sobre a própria vida que o ator $\mathrm{e}$ o autor se sobrepõem, se desdobram sobre si mesmos. É no momento da apresentação de si, que o outro adota a postura de autor-ator consciente da ação cuja responsabilidade é só sua, para expressar os sentidos da sua existência, decidindo o que narrar, como expor, que fatos e eventos merecem destaque ou quais deve ocultar. Para tanto, os autores-atores assumem uma nova percepção de si e dos sentidos atribuídos à vida e ao mundo, ao depararem com a questão sobre como organizar a própria história e escrever sobre si, uma vez que a escrita nem sempre é temporalmente linear.

Esse movimento reflexivo, associado à seleção das expressões e das palavras que serão tecidas no texto, exige escolhas intencionais para organizar a história a ser narrada; e essa escrita de si, quando é compartilhada com um leitor, favorece ao autor um novo olhar sobre suas próprias experiências.

A tecedura da narrativa traz a percepção de que contamos histórias sobre nós próprios e que, sendo assim, a narrativa é compreendida como uma elaboração do pensamento, com palavras artisticamente tecidas para produzir sentidos (BRUNER, 1997). Esse autor enfatiza que a narrativa exige daquele que narra, por via oral ou escrita, um encontro consigo mesmo, antes de dirigir-se ao outro. Essa articulação de ideias parece ser propícia para a construção e para o conhecimento de "nós mesmos". A linguagem, como afirma o autor, é a ferramenta mais poderosa para a organização de experiências e, de fato, para construir as realidades; dessa forma, "a narrativa é também um meio de usar a linguagem" (p.57).

O processo de escrita traduz a memória, o afastamento do que é estranho, o reviver e a exposição de experiência, entre outros aspectos. Segundo Souza (2006, 


\section{N Futbabुa}

ISSN: 1984-6444 | http://dx.doi.org/10.5902/1984644434090

p.144), a escrita do professor sobre si e sobre os saberes de si pode ser um processo árduo para o autor, uma vez que exige colocar-se num movimento de interiorização e exteriorização de suas experiências, assumindo por vezes uma posição de estranhamento, ao realizar "um mergulho interior e o conhecimento de si, a partir dos questionamentos sobre o saber de si a partir do saber-ser e do saber-fazer-pensar sobre o que a vida lhe ensinou".

O próprio narrador seleciona as experiências que foram significativas e formadoras. A produção de narrativa emerge da busca da compreensão de si, confirmando que a narrativa remete para uma incompletude, "exatamente porque a entrada da escrita não tenciona abraçar a totalidade das vivências e aprendizagens formadoras do sujeito, mas sim, aquilo que cada um elegeu como conhecimento de si e como formador na sua vivência pessoal e social" (SOUZA, 2006, p.144).

Para Josso (2004), ao compreendermos que a linguagem utilizada nas narrativas remete à percepção de si, à tomada de consciência de quem somos, esse movimento pode ser considerado uma experiência formadora, visto que a narrativa possibilita articular o saber-fazer com conhecimentos, técnicas e valores, mobilizando o que a autora nomeia de "aprendizagem experiência", que implica "em colocar o sujeito numa prática subjetiva e intersubjetiva no processo de formação" (JOSSO, 2004, p.40). Para ela,

a narrativa escrita apresenta-se como uma tentativa de dar acesso a um percurso interior que evolui correlativamente para um percurso exterior caracterizado por acontecimentos, atividades, deslocamentos, relações contínuas e encontros e pertenças etc. [...] é precisamente na exposição por meio da linguagem das componentes objetivas desse itinerário exterior que se exprime, implícita ou explicitamente, o olhar lançado sobre ele e as dimensões sensíveis que dão cor a essas vivências ou experiências. (JOSSO, 2004, p.186).

As narrativas são potencializadoras de um trabalho formativo e de autoformação desde o momento em que as futuras professoras escolhem as palavras, as cenas e as justificativas das experiências vividas para dialogar entre os pares. Esse movimento dialógico não é tão fácil, pois existe uma dificuldade ímpar para assumirmos e decidirmos as palavras que contam nossas histórias.

A reflexão sobre esse movimento dialógico e, mais especificamente, a dialogicidade existente nas narrativas, nos remetem a Bakhtin (2000), pois, segundo 


\section{N \\ Futfarba}

ISSN: 1984-6444 | http://dx.doi.org/10.5902/1984644434090

o autor, todo discurso é atravessado pelo discurso alheio, e como não bastasse, a propriedade dialógica presente na língua pode disciplinar o discurso, uma vez que, ao narrar se instaura um campo de renegociação e reinvenção da verdade, da história, do tempo, do espaço, dos outros e, principalmente, da subjetividade. As experiências narradas explicitam a dialógica relação entre as subjetividades imbricadas pela história social e cultural de cada um.

Narrar é uma forma de compreender a experiência que se insere no viver, no contar, no reviver e no recontar, em um lugar e um tempo determinados aos quais se reporta o autor/narrador (CONNELLY; CLANDININ,1995).

O professor, ao escrever sobre si, usando a narrativa ou outra modalidade, encontra na escrita uma possibilidade de prática reflexiva: "Um registro escrito de sua prática, serve para proporcionar aos professores um modo de reviver, analisar e avaliar suas experiências no tempo e em relação com outras estruturas de referência mais amplas" (COCHRAN-SMITH; LYTLE, 1999, p.325).

Em outras palavras, a narrativa exposta e analisada criticamente pode se tornar um material da ação e da intencionalidade humana, pois:

ela intermedeia entre o mundo canônico da cultura e o mundo mais idiossincrático dos desejos, das crenças e esperanças. Ela torna o excepcional compreensível e mantém afastado o que é estranho, salvo quando o estranho é necessário como um tropo. Ela reitera as normas da sociedade sem ser didática. E [...] ela provê a base para uma retórica sem confronto. Ela pode até mesmo ensinar, conservar a memória, ou alterar o passado. (BRUNER, 1997, p. 52).

Passeggi (2013) defende que as narrativas possibilitam a desconstrução/construção das experiências tanto dos autores quanto dos possíveis leitores, ao mesmo tempo em que instauram uma relação dialógica e criam cumplicidades de descobertas. As produções autobiográficas vêm se tornando cada vez mais apropriadas para a experiência formadora, porque possibilitam ao autor a compreensão de que, ao "encontrar seu lugar na história coletiva ele retorna a si mesmo para definir suas próprias marcas e fazer sua própria história" (DELORYMOMBERGER, 2008, p. 106).

Ao discutirmos formação e experiência formadora, não podemos deixar de complementar com as ideias de Freire (1997), quando argumenta que formação é um 


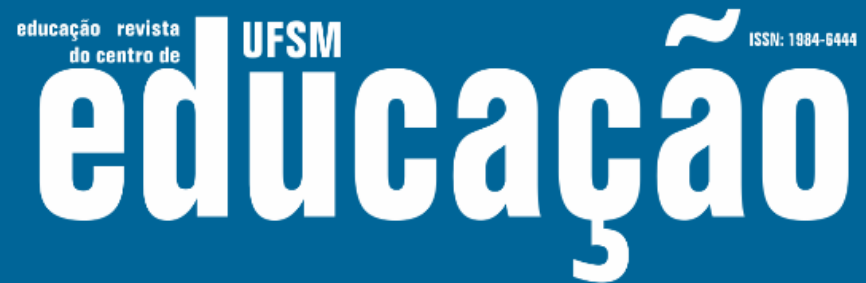

ISSN: 1984-6444 | http://dx.doi.org/10.5902/1984644434090

refazer-se constantemente na ação, normalmente decorrente das conquistas alcançadas mediante muitas ajudas - dos professores, dos livros, das aulas, dos computadores, das trocas entre colegas e da experiência. No entanto, muitas vezes, não se compartilham essas experiências, nem se reflete sobre elas. Daí a importância dos estudos (auto)biográficos, porque eles colocam o professor como protagonista de seu fazer pedagógico e da sua formação. Isso pode ser feito pela escuta atenta do professor pelo formador e/ou pesquisador. Neste artigo buscamos encontrar, na pluralidade das histórias narradas, a autoria de cada futura professora no processo formativo e, consequentemente, problematizar, no âmbito de uma disciplina da graduação, aquelas práticas de ensino de matemática - conhecimento cuja aprendizagem é considerada por muitos como privilégio de pessoas inteligentes - que deixaram marcas negativas ou positivas. A produção de narrativas e a problematização no âmbito da formação inicial podem romper com essas crenças constituídas historicamente nas trajetórias estudantis. Tal ruptura é fundamental para a formação de professores que irão ensinar matemática (NACARATO, 2010).

Nesse sentido, compreendemos que as narrativas autobiográficas podem ser oportunidades ímpares para estimular o desenvolvimento profissional docente, principalmente quando as futuras professoras assumem a responsabilidade de participar como protagonistas de sua formação e refletem sobre as práticas de ensino vivenciadas.

Esses foram os pressupostos que nortearam a produção de dados da presente pesquisa. Assumimos, como professoras e pesquisadoras, o desafio de colocar as futuras professoras no movimento de produção de narrativas autobiográficas, como material para a problematização numa disciplina voltada à formação em matemática.

\section{O contexto de produção das narrativas autobiográficas}

A pesquisa foi desenvolvida em 2014, com 36 futuras professoras, com idades entre 20 e 30 anos, estudantes da 6. ${ }^{\text {a }}$ série, penúltima do curso de Pedagogia de uma instituição privada no interior do estado de São Paulo, na disciplina Fundamentos e Metodologia de Matemática, na qual a primeira autora deste texto atuava como 


\section{Aituanẫ}

ISSN: 1984-6444 | http://dx.doi.org/10.5902/1984644434090

professora. Os dados foram produzidos pela escrita e reescrita de narrativas autobiográficas, totalizando 84 produções.

A partir dos trâmites legais de ética na pesquisa ${ }^{1}$, a professora-pesquisadora sugeriu às alunas a produção de narrativas sobre o processo de escolarização inicial, sobre as aproximações com o ensino e a aprendizagem de matemática e sobre a opção pelo curso de Pedagogia. A pesquisadora, desde o início da pesquisa, levava para as alunas as suas próprias narrativas das aulas, contextualizadas normalmente, a partir de suas lembranças e percepções sobre o ensinar e o aprender matemática.

O pressuposto de que o gênero narrativa exige do narrador selecionar palavras e se envolver no contexto para descrever em detalhes as fases da sua vida, acrescidas de fatos e acontecimentos, trouxe, inicialmente, espanto para as alunas participantes da pesquisa, pois, implicitamente elas teriam que expor suas histórias singulares, mas também plurais, por terem sido vividas em contextos compartilhados e carregados de marcas da cultura social e escolar.

Com a intencionalidade de que as narrativas se tornassem potencializadoras do processo de formação de cada autora, a professora-pesquisadora estabeleceu um acordo inicial com as alunas: em pares - por afinidade - deveriam trocar as narrativas e cada leitora faria considerações e sugestões a partir da sua leitura da narrativa da colega, destacando pontos obscuros ou de descontinuidade. Posteriormente a pesquisadora faria a leitura 'final' e solicitaria a produção da reescrita, se necessário, visando complementar informações fragmentadas, lacunares. Em momento algum houve avaliação dessas produções ou emissão de juízos de valor.

A leitura compartilhada de cada narrativa para a classe ficou a critério da autora, e no início do processo houve certa inibição; posteriormente, todas as alunas fizeram questão de ler as suas histórias. Todo o processo de leitura e análise entre os pares das narrativas foi vivenciado no segundo semestre de 2014 durante os encontros semanais na disciplina, utilizando 30 minutos após as aulas, durante 15 encontros. Nesses espaços aconteceram as leituras e as interpretações das narrativas, bem

\footnotetext{
${ }^{1}$ As alunas assinaram o Termo de Consentimento Livre e Esclarecido, exigido pelo Comitê de Ética na Pesquisa. Nele houve a garantia de anonimato da instituição e dos sujeitos; portanto, usaremos as iniciais dos nomes.
} 


\section{Aithapão}

ISSN: 1984-6444 | http://dx.doi.org/10.5902/1984644434090

como os diálogos que permitiram a produção, pela pesquisadora, do diário de campo e dos demais dados da pesquisa.

Cabe ressaltar que a questão da escolha dos pares, espontaneamente e por afinidade, resultou em mais do que uma estratégia, ou seja, as trocas intencionais afloraram normalmente, sem melindres, pois existia a intencionalidade de que as escritas trouxessem detalhes das trajetórias escolares individuais, como: época, local, tipo de professor e sua relação com os alunos, condições da escola, formas de tratamento recebido, grupo de amigos, rotina de estudo, processos de avaliação e dificuldades encontradas.

A professora-pesquisadora também produziu seu diário, narrando as experiências vivenciadas; por isso, afirmar que foram desenhadas muitas 'cenas de aulas de matemática' durante as leituras das narrativas se justifica como sendo um caminho metodológico adotado durante o processo de produção de dados. Os detalhes e as emoções ficaram imbricados pela cumplicidade do grupo, e as sugestões e os estudos feitos durante o período da pesquisa ampliaram a visualização das experiências em cada leitura, feita pela autora-narradora para as colegas da classe.

Outro detalhe metodológico que se configurou durante a pesquisa e a produção de dados direcionou-se para a produção das narrativas com títulos, uma vez que esse procedimento, que parecia inicialmente não ter grande significado, revelou-se primordial durante o processo de leitura, releitura, reescrita das narrativas autobiográficas.

O título tornou-se um recurso para validação das experiências. A aluna $C D$ convenceu as demais colegas dessa importância, ao anunciar que "o título anuncia o sentido dado à experiência exteriorizada e nós, leitores, (re)significamos o que foi apresentado, tornando nossa experiência ou retomando nossa história de vida". Dentre a enorme gama de significados que essa decisão de se colocar poderia ter, os depoimentos de uma grande maioria de alunas, após ouvirem a narrativa autobiográfica de GK, que trazia o cheiro da merenda como uma das lembranças mais marcantes, foram o marco prático e conclusivo para a importância desse recurso para análise e interpretação do gênero. Nesse instante se confirmou que esse gênero 


\section{Tism Gutrathá}

ISSN: 1984-6444 | http://dx.doi.org/10.5902/1984644434090

contribui como instrumento de autoformação não apenas para o leitor/ouvinte, mas também para o autor. Sendo assim, o movimento reflexivo sobre a importância do título como norteador do conteúdo da narrativa tornou-se um contexto de trocas e produção de significados e interpretações sobre o que sabemos, fazemos e dizemos.

Esse processo pode ser considerado como um esboço das cenas que serão apresentadas, pois desde os primeiros encontros houve discussão sobre a validade da narrativa como instrumento de reflexão sobre si e sobre o que iriam partilhar com o leitor. As experiências vividas, acrescidas das decisões sobre o que escrever e como escrever, ou seja, como compor o texto, são determinantes para o movimento de autocrítica, potencializando aos autores "questões complexas de voz e assinatura", como afirmam Clandinin e Connelly (2011, p.199).

No caso das narrativas autobiográficas desta pesquisa, tais aspectos se ampliaram quando, em meio às exposições que, envoltas pela voz do outro, traziam o lugar, os personagens, o tratamento didático, os cheiros, as emoções e os sentimentos, cada ouvinte se encontrava consigo mesmo, ora em fragmentos das cenas, ora com suas interpretações sobre o momento vivenciado, ora com argumentações sobre a necessidade de acrescentar isso a sua narrativa autobiográfica. Ou seja, as narrativas autobiográficas continuavam a ser construídas por um argumento, pela sugestão de outro título, pela discussão geral, paralelamente às histórias e aos fragmentos de conversas. Esse movimento trouxe singularidade à pesquisa e confirmou a importância das narrativas autobiográficas como instrumento de formação docente.

Para Josso (2004), esse processo de (re)significação atua sobre as experiências e os saberes em ação que vêm sendo produzidos pelos sujeitos que se encontram para falar sobre eles e, nesta pesquisa, ele aconteceu pelo próprio compartilhamento e pela construção coletiva. Isso pode ser explicado de acordo com cada autora, porque o compartilhamento ocorreu por meio do interdiscurso dos sujeitos em interação, cada qual com sua subjetividade.

Cabe acrescentarmos que nem tudo foi muito tranquilo, pois a produção da primeira versão da narrativa, devido à dificuldade de selecionar o que escrever, como escrever, que fatos apresentar, precisou ser retomada, porque as questões temporais 


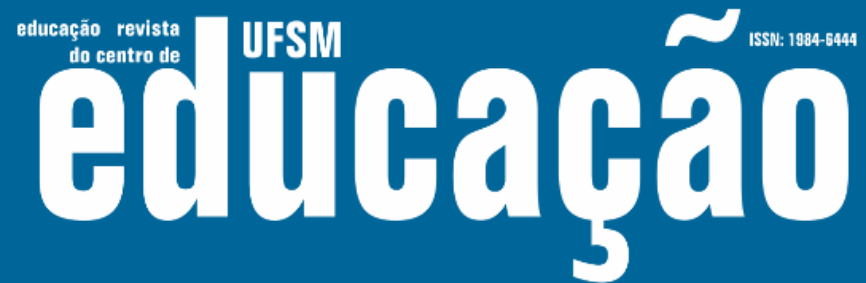

ISSN: 1984-6444 | http://dx.doi.org/10.5902/1984644434090

não apareciam nos textos. Assim, muitas vezes, algumas alunas pareciam não entender o contexto da narrativa, por faltarem detalhes como: quando e onde a autora estudou, como chegava à escola, como era sua professora, quantos alunos havia na classe, entre outros. Logo, algumas alunas, mediante a solicitação das parceiras, produziram duas ou mais versões de sua autobiografia.

As narrativas durante $o$ processo de construção e com as leituras compartilhadas ficaram ricas de detalhes. Neste artigo o recorte centra-se nas marcas da matemática na trajetória escolar, e para tanto, utilizaremos excertos das narrativas autobiográficas, com a indicação de seus títulos reais e das iniciais dos nomes das autoras.

Para o processo de análise das narrativas, fizemos várias leituras de cada uma, fomos identificando as marcas da matemática e construindo cenas de escolarização, algumas das quais foram recorrentes na maioria das escritas das alunas. Para este texto destacamos duas que se sobressaíram: cenas sobre os modos de ensinar matemática e cenas sobre a visão de matemática e o seu papel na sociedade. Procuramos, nos excertos apresentados, não descaracterizar as narrativas produzidas, não fragmentar os sentidos produzidos pelas autoras; dessa forma, alguns deles se apresentam extensos.

\section{Cenas vividas pelas futuras professoras em suas trajetórias estudantis}

A composição das narrativas autobiográficas apresentadas com detalhes referentes aos acontecimentos na escola, aos sentimentos congelados, entre eles alegrias e traumas, e aos silenciamentos, acrescidos do envolvimento recíproco instaurado pelo compartilhar das experiências anunciadas durante as leituras, possibilitou visualizar as cenas com as lembranças, os cheiros e as sensações, entre outros detalhes. Essas cenas, apesar da nostalgia implícita pela complexa e dura realidade desenhada, trouxeram para as participantes a confirmação de que, para grande parte das futuras professoras esteve inalterada, ao longo de seu processo de 


\section{Althapão}

ISSN: 1984-6444 | http://dx.doi.org/10.5902/1984644434090

formação, a forma de relação - não positiva - estabelecida com o professor que ensina matemática.

A compreensão de que, a fim de que os alunos aprendam matemática, o professor precisa propor a eles contextos significativos para a construção de conhecimentos ficou implícita nos registros e, por vezes, nas argumentações orais que emergiram nos momentos de leitura, pois a proposta de produção de narrativa autobiográfica solicitava que as professoras escrevessem sobre suas aproximações com o aprendizado de matemática no início de sua escolarização.

Diante tantos registros marcantes presentes nas autobiografias, optamos por selecionar, a partir do título das escritas de si, histórias que configuraram cenas, conforme anunciado anteriormente, compostas de modos de ensinar matemática, de questões sobre o aprender matemática com adoção de procedimentos didáticos pautados em tendências tecnicistas, muitas vezes recheadas por uma visão ingênua sobre a Matemática, com lembranças intensas desenhadas pelas emoções resultantes do autoritarismo do professor e do silenciamento do aluno.

\section{Cenas sobre os modos de ensinar matemática}

Das 36 alunas participantes, a maioria, ou seja, 28 delas, tinha entre 20 e 30 anos. Sendo assim, sua escolarização ocorreu em um período em que a formação docente já tendia a desprezar a metodologia de ensino pautada no passo a passo e/ou no processo de transmissão e acúmulo de conhecimentos, pois, como aponta Nacarato (2010), essas graduandas ingressaram na escola depois das reformas curriculares da década de 1980, com novas abordagens para o ensino de matemática. Essa década foi considerada um marco nas políticas públicas: o País saía de uma ditadura militar; o construtivismo se consolidava em muitas redes públicas e privadas, principalmente na área de alfabetização, contrapondo-se às propostas tecnicistas que marcaram as décadas anteriores; e a maioria dos estados brasileiros elaborou suas propostas curriculares, em especial, para o ensino de matemática. No entanto, as narrativas revelam, como analisaremos a seguir, que o ensino de matemática parece não ter sofrido transformações; as cenas identificadas são de um ensino ainda marcado pelo autoritarismo, pelo silenciamento dos alunos e pelo tecnicismo. As 


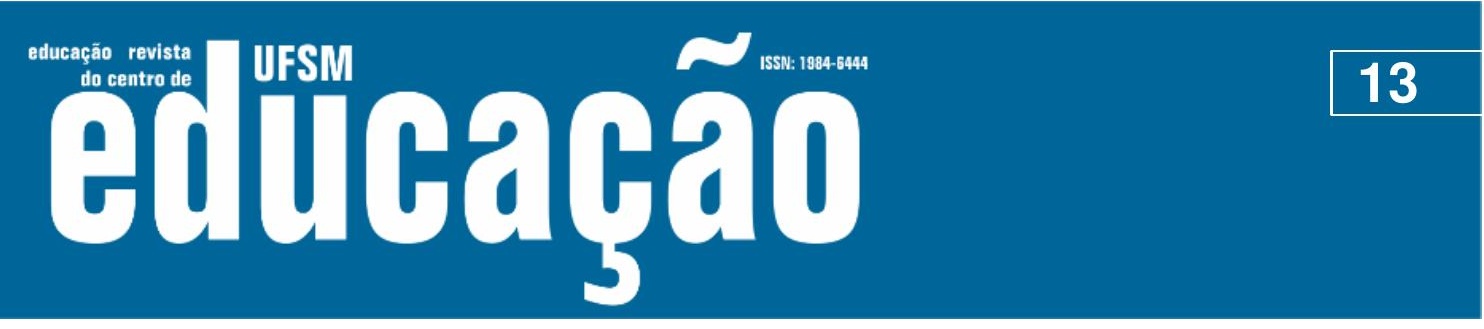

ISSN: 1984-6444 | http://dx.doi.org/10.5902/1984644434090

cenas a seguir analisadas evidenciam os modos como a matemática continuava sendo ensinada e as relações que as futuras professoras estabeleceram com a disciplina, com os professores e com as próprias famílias.

Várias narrativas trouxeram o silenciamento das alunas diante da postura autoritária de professores, como registra EE:

Eu nem perguntava que era para não levar bronca. Então nas provas eu procurava sentar perto de algum aluno e copiava o resultado: acho que para época isso era procurar acertar e passar de ano, não existia na minha cabeça a nossa ideia de que estava 'colando'. (“Eu e a Matemática”, EE).

Muitas vezes, esse autoritarismo era acompanhado de posturas que geravam ofensas morais ou violência simbólica (CHARLOT, 2005), como narra a aluna MS:

Ano 1999 , estávamos na $3 .^{a}$ série e toda quarta feira ela - a professora Joana - fazia chamada oral de tabuada e quando errávamos a classe poderia chamar de 'burro'. Até hoje me lembro do som de muitas crianças gritando essa palavra. Eu, na época, também gritava para meus amigos quando erravam. Parece que esse tempo está distante, mas se passaram apenas 15 anos. ("Burros são aqueles que erram tudo" - MS).

Em outras histórias, os procedimentos esperados dos alunos, associados com o trabalho repetitivo e mecanicista que ocupasse o tempo, se misturavam com a postura autoritária de professores. Uma das alunas trouxe a importância do caderno de ocupação. Descreve que, na época, na cidade do interior do estado do Paraná, os alunos tinham dois cadernos: o de dever e o de ocupação.

O caderno de dever podia ser levado para casa para executar as cópias de textos e mais textos, resolver os inúmeros problemas copiados na classe, fazer as tabuadas e muitas contas armadas, sendo que em casa, quando o dever era de Matemática, tínhamos que colocar o resultado.

O caderno de ocupação era o caderno que ficava na classe e usávamos para os registros de todas as atividades propostas: era permitido levar para casa somente nas vésperas de provas para estudar. Esse caderno de ocupação era apresentado para a diretora, para a inspetora e para as pessoas que visitavam a classe; quando não, a professora usava os cadernos de ocupação de alguns alunos para apresentar a quantidade de 'matéria' dada em classe e o capricho daqueles que ela escolhia.

Meu caderno de ocupação nunca foi escolhido como exemplo para demonstrar para os outros, por mais que eu caprichasse, ou seja, capricho era colorir de azul quando acabava a lição de Português, de vermelho a lição de Matemática, e da cor que preferisse as outras lições. O vermelho da linha colorida do meu caderno se ampliava com os $X$ também em vermelho para as contas com resultados errados ou para os problemas com as respostas em desacordo à pergunta feita. Sendo assim, lembro do meu caderno de ocupação como sendo um material muito trabalhoso sem sentido para mim, por mais que eu me esforçasse na busca dos acertos, então sempre me

Educação | Santa Maria | v. 44 |2019

Disponível em: https://periodicos.ufsm.br/reveducacao 


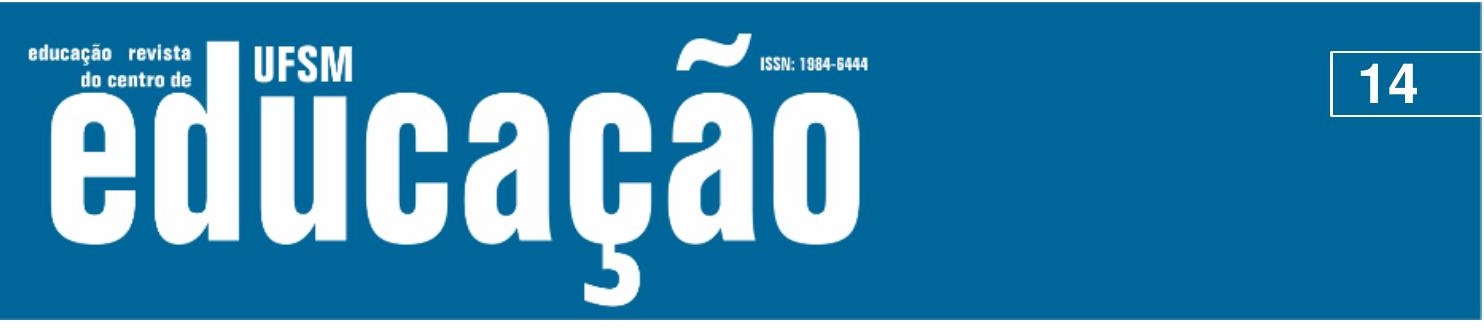

ISSN: 1984-6444 | http://dx.doi.org/10.5902/1984644434090

perguntei: qual o ser humano em sã consciência que faz a continha para errar? Minha relação com a Matemática neste sentido foi amedrontada com os erros e, hoje, entendo que foi distanciada pelos não acertos. ("Meu caderno de ocupação e a Matemática" - TP).

Identificamos também, nas vozes das alunas, que seus professores, na grande maioria, pautaram suas práticas em procedimentos técnicos e utilizaram poder, imposição e até constrangimento aos alunos, para ensinar e alcançar resultados na aprendizagem de conteúdos de matemática.

As narrativas e as discussões orais questionavam o fato de que esses procedimentos ainda estavam presentes no dia a dia das escolas. A aluna ES traz esses aspectos na sua autobiografia e ainda questiona a função de tanto exercício repetitivo.

Eu me questionava, mas tinha que fazer sequência de números e mais números, cheguei a fazer num único dia de 1 até 500 . Era 1998, eu tinha só 8 anos de idade e sentia a obrigação de obedecer a professora Marli, mesmo que não tivesse feito bagunça. Essas tarefas faziam parte da nossa semana, às vezes, mais do que uma vez, tudo dependia do comportamento da classe em qualquer situação: visita de professora da outra sala, se alguém fizesse bagunça/conversasse sobre outro assunto durante a explicação de qualquer matéria, ou se começasse a copiar da lousa antes da professora autorizar, ou ainda se tivesse muita criança sem terminar a atividade dada nos instantes anteriores. Isso me intrigava, pois tudo era em nome do silêncio e de manter os alunos ocupados. ("Escrever de 1 a 100 ...de 1 a 500 ou até mais para quê?" - ES).

Outras cenas de silenciamento diante da autoridade dos professores se misturam com as indagações sobre a exigência de tantos procedimentos e a não compreensão de alguns conteúdos. A narrativa de FF nos traz essa ideia:

A professora Ivanilda pedia para todos cruzarem os braços e para que guardassem os lápis para que não copiássemos o que escrevia na lousa. Sua lousa era bem desenhada, usava giz colorido e sua letra era bem redondinha. Depois que explicava tudo, inclusive quantas linhas tínhamos que pular entre uma atividade e outra, para depois responder, ela deixava iniciar a cópia. Dava um tempo limite, e depois apagava a lousa e enchia de novo, quem não conseguisse terminar de copiar precisava emprestar o caderno do amigo, e se a professora descobrisse aplicava castigo - fazer números, escrever números (como se lê), copiar dez vezes cada tabuada, enfim.

Era tedioso o ensino da época, o medo da professora, da escola, da diretoria, dos bilhetes para os pais, fazia dos alunos uns robozinhos. Lembro-me dos momentos do nosso recreio: os meninos corriam e gritavam como uns loucos, e nós, meninas, ficávamos no canto, senão eles passavam por cima. Quando tocava a campainha, a professora olhava as mãos, para ver se tínhamos lavado. 


\section{N Althapat}

ISSN: 1984-6444 | http://dx.doi.org/10.5902/1984644434090

Eu não me recordo de coisas que aprendi, principalmente de Matemática, pois eram só problemas, de duas ou três contas, contas armadas de divisão e multiplicação. Eu tive aula com essa professora dois anos $-3 .^{a}$ e $4 .^{a}$ série - em 1990 e1991 - só me lembro de uma coisa que até hoje não sei fazer e não precisei para nada: a prova dos nove! ("Tantos recursos e poucas compreensões" - FF).

Outro exemplo de ensino tecnicista é a tabuada. Ela aparece no fazer docente e nas tarefas de muitos alunos e, segundo revelam as análises e as percepções das sessões de audição das narrativas em classe, esses procedimentos ainda são claramente vistos na participação de, no mínimo, 100 horas das futuras professoras nos estágios obrigatórios no ensino Fundamental:

Eu até que gosto de matemática, mas acho impossível falar dessa disciplina e não me recordar das tabuadas. Elas fizeram parte da minha vida escolar intensamente: na escola e em casa fui muito cobrada por fazer e por acertar as tabuadas. Minha mãe me fazia decorar e depois 'tomava', isso quer dizer, pedia algumas, sorteando para verificar se eu sabia todos os resultados. ("A Matemática e a abençoada tabuada" - JH).

Sem dúvida, as cenas aqui apresentadas podem nos remeter ao século passado, quando a escola era para poucos e o ensino era pautado no autoritarismo do professor, muitas vezes acompanhado de castigos físicos. No entanto, estamo-nos referindo ao período de escolarização de final do século $X X$ e início do século $X X I$, com amplo acesso à escolarização de todas as camadas da população. Por que a permanência desses modos de ensinar matemática? Quais as contribuições que as pesquisas têm trazido para as práticas dos professores? São questões que continuam nos inquietando.

\section{Cenas sobre a visão da matemática escolar e do seu papel na sociedade}

A natureza da matemática e a contextualização das imagens apresentadas pelas alunas do curso de Pedagogia podem ser destacadas em alguns excertos de narrativas que demonstram a concepção ingênua das alunas e futuras professoras em relação à prática educativa. Em muitas narrativas há o fortalecimento do discurso de que sucesso em matemática escolar é futuro garantido, e a matemática é para poucos, os inteligentes.

Algumas graduandas anunciaram que ficava claro no discurso dos adultos professores e familiares - que os meninos eram mais inteligentes e por isso aprender 


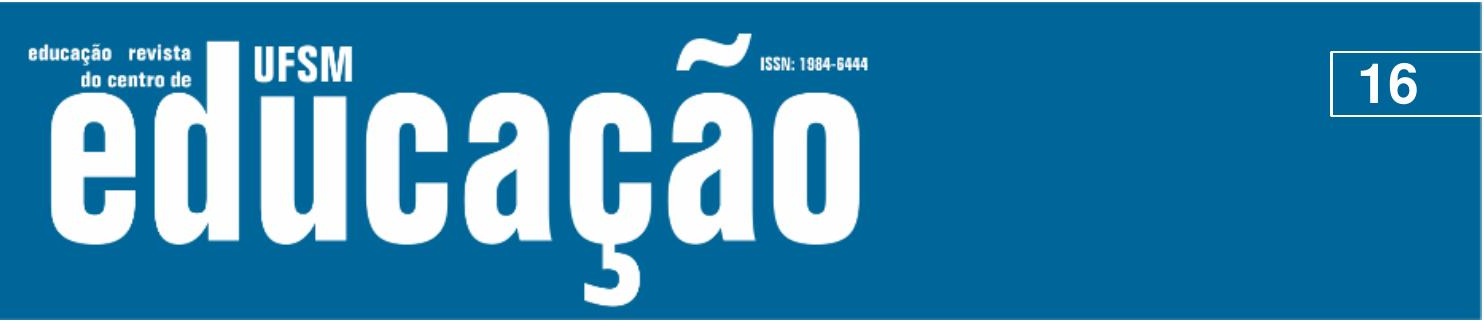

ISSN: 1984-6444 | http://dx.doi.org/10.5902/1984644434090

conteúdos de Matemática era mais fácil para eles. Provavelmente, essa afirmativa, de tanto ser ouvida, era tida como verdade. Outra verdade associada a essa e legitimada nos discursos é a referente à afirmação de que o desempenho nota 10,0 (dez) em matemática tinha como resultado 'um futuro garantido'. Para muitas alunas, quando da problematização desse discurso, elas ainda acreditavam que 'matemática é para homens inteligentes que normalmente encontram empregos bem remunerados'. Tal concepção se fez presente na narrativa de JB:

Sempre, seja na família ou na escola, ouvia a frase: matemática é para os inteligentes! Eu me esforçava, mas não conseguia acertar todas as inúmeras contas, ou os dez problemas de dever, ou até mesmo, na chamada oral da tabuada, acertar todas as fichas tiradas. As professoras eram exigentes e a rapidez no cálculo - algoritmo - e a ordem das contas para resolver os problemas eram avaliados e lembro-me que sempre um ou outro menino se sobressaía, não dando a vez para as meninas.

Recordo-me do jeito que as professoras exigiam a resolução: do lado esquerdo, sentença matemática, um traço na vertical; e, do lado direito da folha, as operações. As respostas deveriam começar com o sujeito e o verbo da pergunta: sempre no final deveríamos colocar respostas bem elaboradas e, mesmo que soubesse o resultado do problema, esses procedimentos precisavam ser cumpridos.

Eu pensava comigo mesmo: tenho que acertar, tenho que fazer caprichado e ter tudo em ordem, mesmo que eu copie a resposta do meu amigo, pois a professora Gildete gosta assim. Então me perguntava: mas se eu não entendi? O que eu faço? Uma coisa eu tinha certeza: nunca seria uma pessoa com o futuro garantido. (“As aulas de Matemática e o meu futuro!!" $\mathrm{JB})$.

Ter um bom desempenho em matemática também marcou a trajetória de algumas graduandas.

Eu sempre copiava o resultado das contas dos meus amigos, principalmente os resultados das divisões. Algumas vezes eu chorei, em sala de aula, por não conseguir resolver as contas de dividir. Com o tempo desisti de tentar resolver, então esperava a professora corrigir na lousa ou copiava dos amigos. Minhas tias me ensinavam os deveres de casa, e muitas vezes faziam para eu copiar. Até nos dias das provas, ou eu errava todas e acertava os demais exercícios ou eu 'colava' os resultados. Minha salvação até hoje é a existência da calculadora. Essa não compreensão sempre mantive em segredo. De verdade somente hoje consigo fazer esse anúncio, ou essa denúncia: não sei bem como escrever!

Minha família, na época, se soubesse dessa minha dificuldade ou do que eu fazia para tirar nota ficaria muito triste, ou melhor, acho que meu pai me daria umas boas palmadas. Para ele, na escola e nas boas notas estava o meu futuro. ("A divisão me separando da Matemática" - AA). 


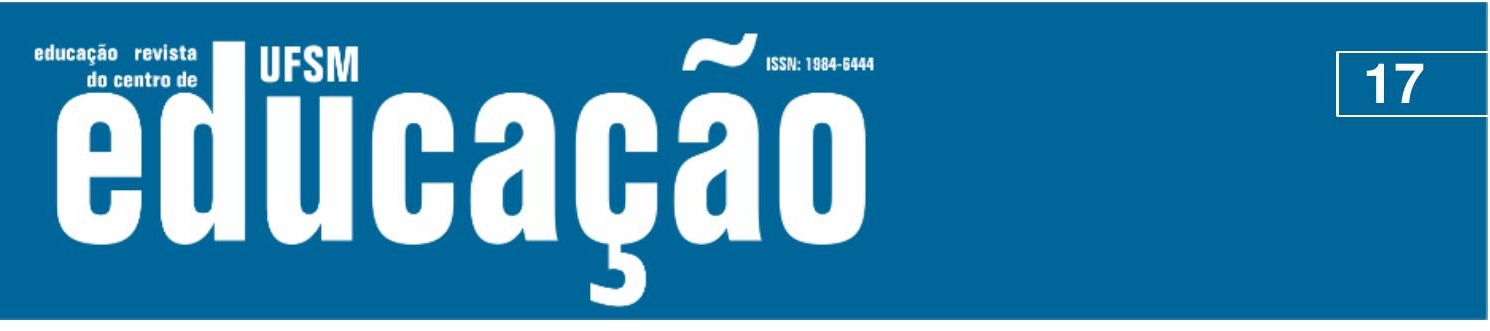

ISSN: 1984-6444 | http://dx.doi.org/10.5902/1984644434090

Outras narrativas se referem à conservação da utopia de achar que apenas a educação pode transformar a sociedade e mudar a situação da desigualdade. Uma delas, a da aluna GO, ilustra parcialmente essa concepção, além de se referir aos saberes docentes das professoras da época. Ela trouxe para reflexão a importância de saber articular a situação-problema com os exemplos do cotidiano, afirmando que o fazer pedagógico se aproximava do conteúdo específico, na intenção de garantia de um futuro melhor:

Minha infância foi bem divertida. Tive excelentes professores. Estudei na préescola na escola do município considerada modelo para época - 1993-1997. $[\ldots]$

As professoras que tive depois do Ensino Fundamental também foram excelentes, e o que eu posso afirmar é que elas buscavam sempre fazer experiências com números e quantidades no concreto e que os registros na folha eram coisas que vinham por consequência das atividades feitas. Não tínhamos que copiar os problemas e sim resolvê-los, a partir da leitura da professora, quando ainda não sabíamos ler. Foi um começo de aproximação com a Matemática "escolar" bem interessante, e entendo que o futuro de muitos alunos em relação à aprendizagem de matemática, principalmente, para aqueles que participavam das aulas e faziam as tarefas, foi garantido nas escolas que estudei. ("Minha infância e a matemática" - GO).

Mesmo com os investimentos, nas últimas décadas, para produção de documentos e propostas curriculares acrescidas de ações de formação docente pautadas em discussão sobre o processo de aprendizagem para eliminar a hierarquização dos conteúdos, os ditos pré-requisitos de aprendizagem, não foi raro encontrar nas narrativas autobiográficas a interpretação de que existe uma estrutura lógica da Matemática, que desconsidera as potencialidades dos alunos e exige uma prontidão para aproximação com os conteúdos matemáticos.

A narrativa da aluna EE traz a concepção de que, por exemplo, o ato de aprender conceito de fração em matemática depende exclusivamente das aproximações anteriores dos alunos com os números e as operações, e aqueles alunos cujos professores eram 'bravos' e exigentes desenvolviam bloqueios para aprendizagem de conceitos matemáticos mais 'difíceis'.

[...] lembrando minha sala de aula do $4 .^{\circ}$ ano, eu entendo que a professora da $4 .^{\text {a }}$ série [a aluna se refere a 2003] ficava nervosa com alguns alunos que nem sabiam divisão e que na hora de entender as frações não se comportavam na classe e ela mandava fazer tabuadas. A professora precisava dar o conteúdo e os alunos não entendiam e ela não tinha outras opções. Hoje compreendo que ela poderia fazer as aproximações com o 


\section{N Fithapac}

ISSN: 1984-6444 | http://dx.doi.org/10.5902/1984644434090

conceito de frações no concreto e depois faria cálculos reais: por exemplo, um terço de todos os alunos da classe, sendo que a classe tem 30 alunos. ("Minha infância e a escola" - EC).

A família também aparece nas narrativas das futuras professoras, ora por cobranças pelo sucesso na escola, ora pela expectativa de que os estudos possibilitem uma vida melhor. A narrativa de MR, por exemplo, revela o sacrifício dos pais para os filhos frequentarem a escola e serem aprovados:

Nunca fui boa aluna de Matemática: somente as aulas particulares pareciam ser minha salvação, pois sempre tive dificuldades para aprender Matemática, mesmo que eu prestasse atenção. Até hoje não sei fazer conta de dividir com dois algarismos e muito menos com número com vírgula.

Minha mãe tinha que pagar aulas particulares, normalmente gostava que essas aulas fossem dadas pela mesma professora que dava aula para mim, para eu saber o que iria cair na prova e, então, ser aprovada.

Lembro-me da professora Aparecida, que me deu aula particular e no dia da prova ela faltou: me deu branco. Eu até sabia algumas contas, mas tinha muito medo de errar!

Não gosto muito de contar minhas lembranças escolares. Tive dificuldades e pouca ajuda, ou melhor, compreensão das professoras. Minha mãe era analfabeta e tinha um pouco de dinheiro porque meu pai trabalhava na Fepasa e ganhava mais ou menos bem, mas ela pensava assim: sem estudos meus filhos não têm futuro garantido, serão como eu!

Eu escolhi ser professora, pois quero fazer a diferença, vou analisar o que o aluno traz da família, penso, e verificar o que ele sabe dos conteúdos novos e explicar quantas vezes forem necessárias. ("Eu e Matemática e a escolha da profissão docente" - MR).

O acompanhamento do desempenho escolar pelos pais também foi destacado, em algumas narrativas, como algo importante:

Sou filha de pais separados. Meu pai era fisioterapeuta e sempre quis que eu estudasse em escola particular. Eu sempre tive poucos amigos porque estudava com 8 ou 10 alunos na classe. [...] A escola e as professoras acompanhavam nossas atividades e tinham o compromisso de expor para nossos pais tudo o que aprendíamos. Até algumas perguntas da sala de aula elas usavam para ilustrar nosso dia a dia.

Minha mãe, quando ia me buscar, esperava no carro, senão a professora queria contar tim-tim por tim-tim para ela. Fiquei nessa escola até a $8 .^{a}$ série. Continuei com meus amigos e até hoje sinto falta desse cuidado que eu recebia. ("Momentos inesquecíveis" - BG).

Esse acompanhamento, algumas vezes, podia resultar em castigos que a família aplicava. A aluna GK apresenta boas lembranças da escola; no entanto, se 


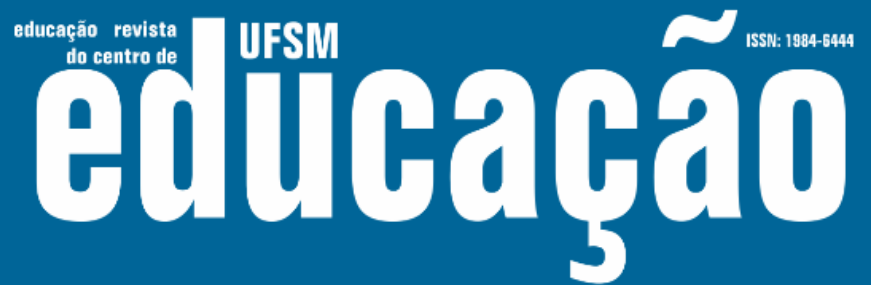

ISSN: 1984-6444 | http://dx.doi.org/10.5902/1984644434090

recorda da imagem do seu pai olhando os cadernos todos os dias e solicitando-Ihe que ficasse fazendo tabuada:

[...] para meu pai a tabuada deveria ser decorada desde o $1 .{ }^{\circ}$ ano. Eu ficava até encolhida quando ele me dava um lápis bem apontado e falava para eu fazer dez vezes cada tabuada, e no final eu fazia uma chamada oral.

Eu adorava a escola e fazer dever, mas não gostava deste castigo: a bendita tabuada para decorar! Posso afirmar que essa condição imposta pelo meu pai me deixou desanimada.

Quando eu aprendi a tabuada pensei que iria me livrar, ele me pediu para acompanhar e ensinar minha irmã mais nova. Até hoje tenho receio de fazer contas de multiplicação e divisão. Instaurou-se um bloqueio em mim! ("A tabuada e a matemática" - GK).

A identificação dessas cenas nos leva a concordar com Charlot (2005) que os alunos estabelecem relações com os professores e não com o conhecimento; muitas cenas nos dão pistas de que a escolarização é marcada pelas relações interpessoais e o papel do professor vai além do trabalho com o conhecimento específico. É nessas relações sociais estabelecidas na trajetória estudantil que construímos nossas crenças sobre a escola, as diferentes disciplinas do currículo, os modos de relacionamento e os modos de ensinar.

Muitas outras cenas se desenharam nas narrativas produzidas. No entanto, estas aqui apresentadas são suficientes para nos dar pistas de como têm se configurado as práticas de ensino de matemática. Quais as implicações dessas pistas para a formação docente?

\section{Para concluir: os desafios postos para a formação de professoras que ensinam matemática}

As narrativas autobiográficas transmitiram valores e revelaram tensões e impasses presentes no cotidiano escolar, que resultam em dúvidas sobre as aproximações com os conhecimentos matemáticos, uma vez que a ação do professor exposta na maioria das narrativas autobiográficas, se vista pelo prisma ético, teórico e prático, define um descontentamento geral e uma perda de entusiasmo pelo aprendizado e pelo ensino da matemática, em decorrência de práticas educacionais 


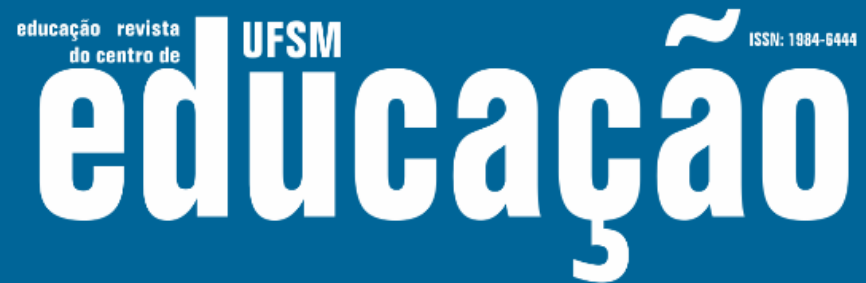

ISSN: 1984-6444 | http://dx.doi.org/10.5902/1984644434090

formais, rígidas, autoritárias, referendadas num sistema de ensino excludente e reprodutivista.

Mesmo nos momentos de discussões e compartilhamentos dessas experiências vivenciadas, as alunas manifestavam certo negativismo diante de práticas ainda hoje vigentes nas escolas, gerando desconforto para ensinar e aprender matemática.

As vozes das futuras professoras precisavam ser retomadas com conteúdos matemáticos a ser trabalhados em sala de aula com os alunos, de forma a garantir que existam, para ser trilhados pela ação docente, caminhos destituídos de configurações que enrijecem o fazer pautado nos exercícios de fixação, nas cópias de tabuadas e no descaso com os alunos que não se identifiquem com a Matemática. Porém, as narrativas traziam tantas emoções, sentimentos e traumas que ficou prejudicado o ambiente de discussão teórica e de prática segundo os princípios da educação matemática que favorecem a investigação e a construção de conhecimentos sobre os conteúdos matemáticos.

No entanto, o contexto criado em sala de aula para que as graduandas produzissem suas narrativas, compartilhassem com as colegas e problematizassem as práticas vivenciadas, constituiu-se em um espaço de formação. O movimento reflexivo vivido pelas futuras professoras, com certeza, deixou marcas sobre os modos de ensinar matemática: algumas delas, talvez, buscarão outros caminhos em suas salas de aula; outras continuarão reproduzindo aquilo que vivenciaram como estudantes da escola básica. Esse é o desafio que fica para a formação continuada: romper com as crenças arraigadas que não foram alteradas na formação inicial.

Após as reflexões produzidas neste texto fica a indagação: onde estão as mudanças conquistadas com, no mínimo, três décadas de estudos e investimentos nas reformas curriculares e na formação de professores que ensinam matemática?

Tais constatações precisam ser levadas para a reflexão sobre a forma como tem sido ministrada a disciplina de Fundamentos e Metodologia do Ensino de Matemática no curso de Pedagogia. Como destaca Nacarato (2010), se não houver rupturas nas crenças dos futuros professores sobre o que seja ensinar matemática e sobre a natureza do conhecimento matemático escolar, continuaremos formando 


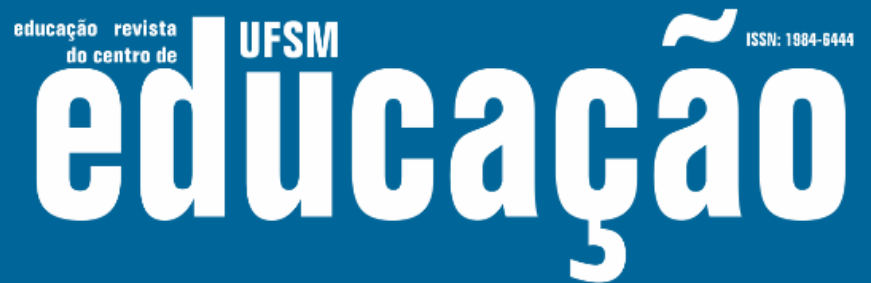

ISSN: 1984-6444 | http://dx.doi.org/10.5902/1984644434090

professores que reproduzirão as práticas vivenciadas como estudantes, perpetuando um ensino tecnicista e sem sentidos para os alunos.

Esta pesquisa nos traz indícios sobre o distanciamento existente entre as políticas públicas e o cotidiano das escolas. Orientações e discussões sobre um ensino de matemática que produza sentido aos alunos não chegam à maioria das escolas. Perspectivas de ensino de matemática pautado na resolução de problemas, em práticas investigativas e nos processos de elaboração conceitual, contrapondo-se a modelos tecnicistas de ensino, precisam ser objeto da formação - inicial e continuada - de professores.

\section{Referências}

BAKHTIN, Mikhail. Estética da criação verbal. 3. ed. São Paulo: Martins Fontes, 2000.

BRUNER, Jerome. Atos de significação. Trad. Sandra Costa. Porto Alegre: Artes Médicas, 1997.

CHARLOT, Bernard. Relações com o saber, formação dos professores e globalização: questões para educação hoje. Porto Alegre: Artmed, 2005.

CLANDININ, D. Jean; CONNELLY, F. Michael. Pesquisa narrativa: experiências e história na pesquisa qualitativa. Tradução do Grupo de Pesquisa Narrativa e Educação de Professores ILEEL/UFU. Uberlândia: EDUFU, 2011.

COCHRAN-SMITH, Marilyn; LYTLE, Susan Landy. Relationships of knowledge of practice: teacher learning in communities. Review of Research in Education, USA, n. 24, p.249-305, 1999.

CONNELLY, F. Michael; CLANDININ, D. Jean. Relatos de experiencia e investigación narrativa. In: LARROSA, Jorge et al. Déjame que te cuente: ensayos sobre narrativa y educación. Barcelona: Laertes, 1995. p. 11-59.

DELORY-MOMBERGER, C. Biografia e educação: figuras do indivíduo projeto. Trad. Maria Conceição Passegi, João Gomes da Silva Neto e Luis Passegi. Natal: Ed. UFRN; São Paulo: Paulus, 2008.

FREIRE, Paulo. Pedagogia da indignação: saberes necessários à prática educativa. São Paulo: Paz e Terrra, 1997.

JOSSO, Marie-Christine. Experiências de vida e formação. São Paulo: Cortez, 2004. 


\section{Aีtloapã̃}

ISSN: 1984-6444 | http://dx.doi.org/10.5902/1984644434090

NACARATO, Adair M. A formação matemática das professoras das séries iniciais e a escrita de si como prática de formação. Bolema - Unesp, Rio Claro, v. 23, n. 37, p. 905-930, dez. 2010.

PASSEGGI, Maria da Conceição. Narrar é humano! Autobiografar é um processo civilizatório. In: PASSEGGI; Maria da Conceição; SILVA, Vivian Batista da. (Org.). Invenções de vida, compreensão de itinerários e alternativas de formação. São Paulo: Cultura Acadêmica, 2010. p. 103-130.

PINEAU, Gaston. As histórias de vida em formação: genese de uma pesquisa-açãoformação existencial. Educação e Pesquisa, São Paulo, v.32, n.2, p. 329-343, maio/ago. 2006.

SOUZA, Elizeu C. Pesquisa narrativa e escrita (auto) biográfica: interfaces metodológicas e formativas. In: SOUZA, Elizeu C.; ABRAHÃO, Maria Helena B. Tempos, narrativas e ficções: a invenção de si. Porto Alegre: Edipucrs, 2006. p. 135147.

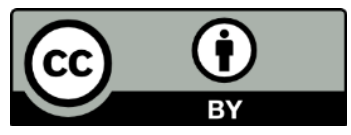

This work is licensed under a Creative Commons Attribution 4.0 International (CC BY 4.0). 